\title{
Terminologišče - kraj, kjer terminolog išče
}

\author{
MOJCA ŽAGAR KARER \\ Inštitut za slovenski jezik Frana Ramovša ZRC SAZU, Novi trg 4, \\ SI-1000Ljubljana,mojca.zagar@zrc-sazu.si
}

\begin{abstract}
SCN VIII/1 [2015], 22-33
Terminologišče je spletišče Sekcije za terminološke slovarje Inštituta za slovenski jezik Frana Ramovša ZRC SAZU, ki poleg predstavitve sekcije in njenih slovarskih projektov, kratkega opisa metodologije izdelave terminoloških slovarjev in izbora terminološke teorije vsebuje iskalnik po 10 razlagalnih terminoloških slovarjih, ki so v tiskani obliki izšli po letu 2000. Poleg tega ponuja tudi terminološko svetovanje, ki je namenjeno reševanju aktualnih terminoloških zadreg strokovnjakov. V prispevku je predstavljena zasnova in izvedba Terminologišča.
\end{abstract}

Terminologišce is a website of the Terminological Section of the Fran Ramovš Institute of the Slovenian Language where one can find a presentation of the Section and its dictionary projects, a short description of the methodology used for making terminological dictionaries, and a selection of terminological theory. Moreover, the website hosts a search engine where one can browse 10 explanatory terminological dictionaries that were published in printed form the year 2000 onward. It also offers terminological advice to experts on terminological issues. In this article we present the design and construction of Terminologišče.

Ključne besede: terminologija, terminološki slovar, terminološko svetovanje, Terminologišče

Key words: terminology, terminological dictionary, advising on terminology, Terminologišče

\section{Uvod}

Urejena in usklajena terminologija je bistvena za učinkovito sporazumevanje med strokovnjaki. To pomeni, da so njeni primarni uporabniki strokovnjaki, po drugi strani pa je kot sestavni del jezika zanimiva tudi za jezikoslovce. Nenazadnje si termini, ki označujejo strokovne pojme, velikokrat utrejo pot $\mathrm{v}$ jezik množičnih medijev in tako postanejo del jezika vseh govorcev, ne le strokovnjakov. ${ }^{1}$ Zato ni nenavadno, da v našem prostoru in drugod poteka veliko

\footnotetext{
${ }^{1}$ Gre za proces determinologizacije, natančneje opisan npr. v M. Žagar Karer (2005: 35-48).
} 
terminoloških aktivnosti. Pogled v bibliografski sistem Cobiss pokaže, da je po letu 2000 pri nas izšlo več kot 180 terminoloških slovarjev² - od seznama nekaj deset terminov do poglobljenih slovarskih projektov, ki zajemajo terminologijo temeljnih strok in pri katerih je sodelovalo večje število priznanih strokovnjakov. Terminološki slovarji so poleg tiskanih izdaj vse pogosteje dostopni tudi na spletu, bodisi kot samostojni slovarji, kot je npr. I-slovar (http://www. islovar.org/slovar_oslovarju.asp), bodisi v okviru večjih slovarskih portalov, ki združujejo slovarje različnih tipov, kot je npr. Termania (http://www.termania. net/). Druga velika skupina uporabnikov terminoloških virov so prevajalci, ki terminologijo pogosto urejajo za svoje potrebe. Če želijo prevajalci ustrezno prenesti strokovno vsebino iz enega $\mathrm{v}$ drugi jezik, potrebujejo urejeno in konsistentno terminologijo, sicer lahko pride do velikih težav. Primer terminološkega vira, namenjenega zlasti prevajalcem, je npr. večjezična terminološka zbirka Evroterm (http://www.evroterm.gov.si/).

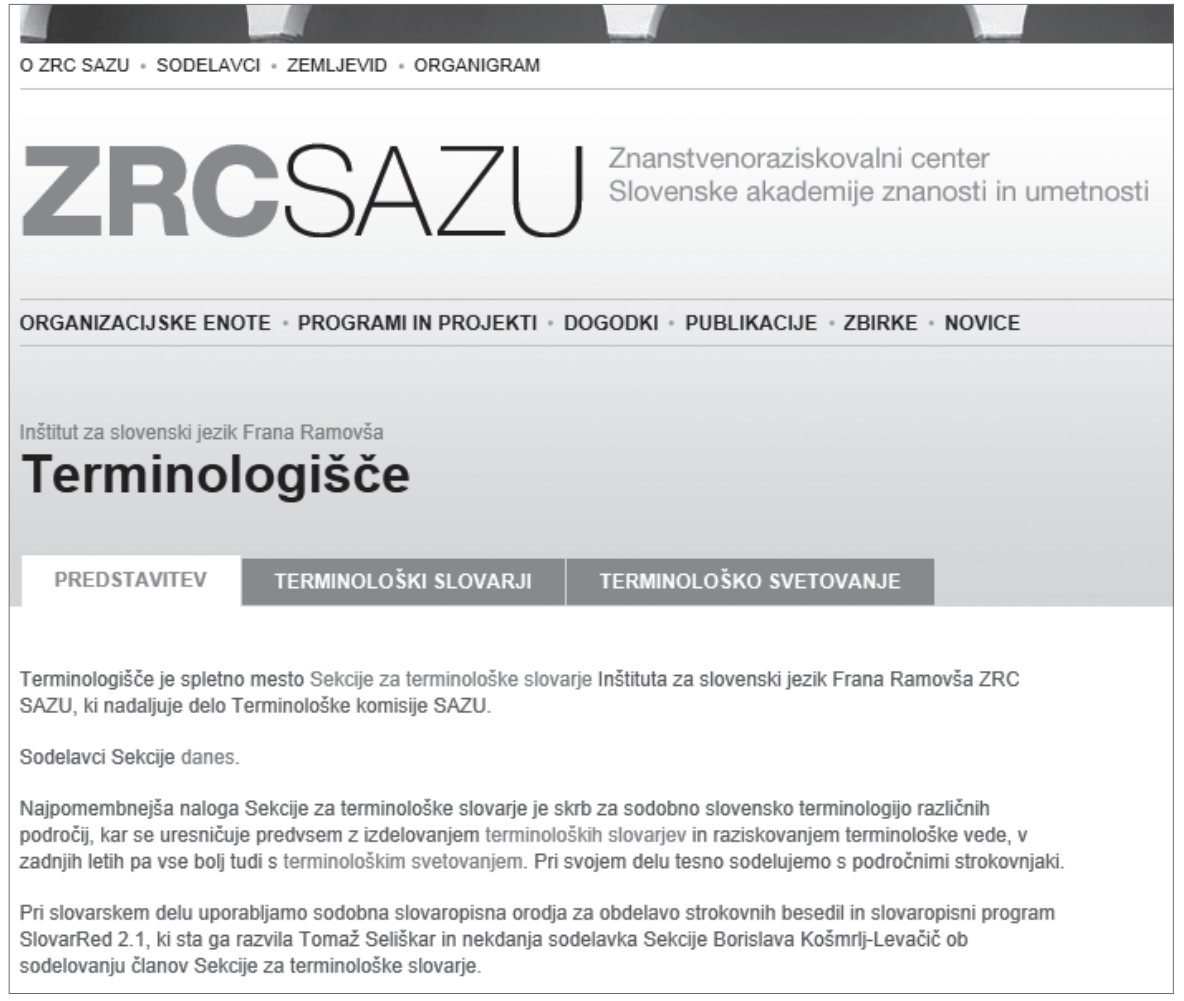

Slika 1: Osnovna stran.

${ }^{2}$ Upoštevani so tiskani in elektronski slovarji. 
Kljub množici na spletu dostopnih terminoloških virov, ki pa so razpršeni in pogosto slabo dokumentirani, ${ }^{3}$ je za uporabnike pomembna tudi večja dostopnost relevantnih terminoloških virov. Zato smo se na Sekciji za terminološke slovarje Inštituta Frana Ramovša ZRC SAZU odločili, da razlagalne terminološke slovarje, ki so po letu 2000 pri Založbi ZRC izšli v knjižni obliki, objavimo še v prostodostopni elektronski obliki. Ker je bila to priložnost za temeljit premislek o tem, kako predstaviti delo Sekcije za terminološke slovarje, ${ }^{4}$ smo se odločili, da bomo poleg iskalnika po terminoloških slovarjih zainteresiranim uporabnikom ponudili še dodatne informacije o terminologiji. Tako je nastalo spletno mesto Terminologišče (http://isjfr.zrc-sazu.si/terminologisce), katerega zasnovo in izvedbo bomo predstavili v tem prispevku. Slika 1 prikazuje osnovno stran.

Terminologišče je razdeljeno na tri dele, ki se medsebojno dopolnjujejo. Predstavljeni so tekoči projekti sekcije, uporabnik lahko išče po 10 terminoloških slovarjih različnih strok, poleg tega pa lahko dobi tudi terminološki nasvet.

\section{Predstavitev Sekcije za terminološke slovarje}

\subsection{Metodologija izdelave terminoloških slovarjev}

Prvi zavihek je namenjen predstavitvi dela Sekcije za terminološke slovarje. Na kratko je opisana metodologija izdelave terminoloških slovarjev. Terminološki slovarji nastajajo v tesnem sodelovanju s področnimi strokovnjaki, saj smo prepičani, da je njihovo poglobljeno znanje bistveno za strokovno relevantnost končnega izdelka. Slovarsko delo sicer od začetka do konca vodi terminograf. Skupaj s sodelujočimi področnimi strokovnjaki določi koncept slovarja in na podlagi izbranih strokovnih besedil s pomočjo korpusnih orodij izdela geslovnik, ki je dokončno oblikovan v sodelovanju s področnimi strokovnjaki. Nato se začne oblikovanje slovarskih sestavkov, ki poteka po pojmovnih skupinah. Definicije terminov in tujejezične ustreznike prispevajo strokovnjaki, ki s svojim znanjem zagotavljajo strokovno verodostojnost informacij. V zvezi s tujejezičnimi ustrezniki je treba poudariti, da strokovnjaki terminov ne prevajajo, ampak poiščejo ustreznen termin v drugem jeziku. Ker področni strokovnjaki, s katerimi sodelujemo, praviloma dobro poznajo (vsaj) angleško terminologijo, pri tem večinoma ni težav. ${ }^{5}$ Terminograf skrbi za jezikovno stran terminologije

\footnotetext{
${ }^{3}$ Mnogi terminološki slovarji in slovarčki na spletu nimajo niti najosnovnejših podatkov o avtorju, zasnovi in zgradbi slovarja.

${ }^{4}$ Za predanost projektu se zahvaljujem vsem sodelavcem sekcije, še posebej pa doc. dr. Mateji Jemec Tomazin.

${ }^{5}$ Večje težave se lahko pojavijo v drugi smeri, tj. da strokovnjaki ne poznajo slovenskih terminov ali pa ti sploh ne obstajajo. Tako ni redko, da slovenski strokovnjaki v medsebojnih pogovorih uporabljajo kar angleške termine. Na ravni terminologije se to odraža tudi pri terminih, ki kombinirajo slovensko in angleško sestavino, npr. in-house naročilo na področju javnega naročanja ali on-off regulator $\mathrm{v}$ avtomatiki.
} 
(jezikovnosistemska ustreznost terminov, onaglasitev iztočnic v skladu s pravili slovenskega jezika, slovnični podatki, sprotni jezikovni pregled definicij), opozarja pa tudi na usklajenost definicij in na morebitne pojmovne nedoslednosti ter tako skrbi za koherentnost terminološkega sistema, ki se kaže v slovarju. Usklajevalni pregled poteka $\mathrm{v}$ tesnem sodelovanju terminografa in strokovnjakov, delo pa se zaključi s tiskano in/ali elektronsko izdajo. Popravki, dopolnila in komentarji končnih uporabnikov so upoštevani v naslednjih izdajah slovarjev. Več o metodologiji izdelave terminoloških slovarjev v Sekciji za terminološke slovarje npr. v T. Fajfar (2013: 97-103) in B. Košmrlj-Levačič (2009: 163-176; 2007: 583-598).

Pri slovarskem delu uporabljamo slovaropisni program SlovarRed 2.1, ki sta ga razvila Tomaž Seliškar in nekdanja sodelavka sekcije Borislava Košmrlj-Levačič ob sodelovanju drugih članov Sekcije za terminološke slovarje. Program je namenjen vnašanju, urejanju in izpisovanju terminov po različnih kriterijih in končni pripravi besedila za tisk oz. pripravi baze za elektronsko objavo.

\subsection{Izbor znanstvenih prispevkov s področja terminologije}

V okviru prestavitve sekcije smo dodali tudi seznam, ki vsebuje izbor znanstvenih člankov in monografij sedanjih in nekdanjih sodelavcev sekcije. Sodelavci sekcije se namreč ob praktičnem slovarskem delu ukvarjamo tudi s terminološko teorijo, saj menimo, da je prenos spoznanj iz slovarske prakse v teorijo zelo pomemben. Seznam bi lahko sčasoma dopolnili tudi s prispevki drugih slovenskih raziskovalcev, ki se ukvarjajo s terminologijo, in tako dobili celovit pregled terminološke teorije pri nas. Tak seznam bi bil koristen zlasti za študente jezikoslovja, prevajalstva in novinarstva, ki se s terminologijo srečujejo znotraj svojih študijskih programov.

\subsection{Kratka predstavitev nastajajočih slovarjev}

Trenutno v sekciji nastaja več terminoloških slovarjev različnih strok in različnih obsegov. Največji aktualni slovarski projekt je Pravni terminološki slovar. Obsežna slovarja sta tudi Terminološki slovar živinoreje in Terminološki slovar agronomije. Prav tako po obsegu izstopa Splošni tehniški slovar, ki zajema terminologijo več tehniških strok. Nekoliko manjši slovarji so Terminološki slovar uporabne umetnosti - pohištvo, ure, orožje (izid je predviden v prvi polovici leta 2015), Urbanistični terminološki slovar (izid je predviden do konca leta 2015), Terminološki slovar armiranobetonskih konstrukcij, Tiflopedagoški terminološki slovar, Slovar barv in Pravnozgodovinski slovar.

$\mathrm{Za}$ vse nastajajoče terminološke slovarje smo dodali še nekaj osnovnih informacij o projektu: ime sodelujoče organizacije; ime terminografa, ki vodi projekt; imena področnih strokovnjakov, ki sodelujejo pri slovarju; glavno področje in podpodročja, ki jih slovar obravnava; faza dela (izdelava geslovnika, obdelovanje slovarskih sestavkov, usklajevalni pregled, priprava na izdajo). 
Med novostmi opozorimo na nekaj slovarjev, ki so izšli v zadnjih dveh letih. Jeseni 2013 je izšel obsežen Veterinarski terminološki slovar, ki je zaradi strukture slovarja, ki odstopa od strukture drugih terminoloških slovarjev, ki nastajajo v sekciji, še v pripravi na elektronsko izdajo. Spomladi 2014 je izšel Tolkalni terminološki slovar, ki bo zaradi določila v pogodbi s soizdajateljema (Društvo slovenskih skladateljev, Društvo Slovenski tolkalni projekt) v elektronski različici izšel šele spomladi 2016. Drugi slovar, ki je jeseni 2014 v knjižni obliki izšel v sekciji, je Terminološki slovar avtomatike - slovar je bil dva meseca po izidu objavljen tudi v elektronski obliki na Terminologišču.

\section{Terminološki slovarji}

Pod drugim zavihkom lahko uporabniki Terminologišča najdejo prostodostopne elektronske verzije 10 razlagalnih tiskanih slovarjev, ki so izšli v Sekciji za terminološke slovarje od leta 2000 naprej. V celoti so objavljeni naslednji slovarji: Terminološki slovar avtomatike, Botanični terminološki slovar, Farmacevtski terminološki slovar, Slovenski smučarski slovar, Gledališki terminološki slovar, Čebelarski terminološki slovar, Geološki terminološki slovar, Gemološki terminološki slovar, Geografski terminološki slovar in Planinski terminološki slovar. Slovarji skupaj vsebujejo več kot 50.000 iztočnic z definicijami ali kazalkami na prednostne termine in ustrezniki $v$ različnih jezikih.

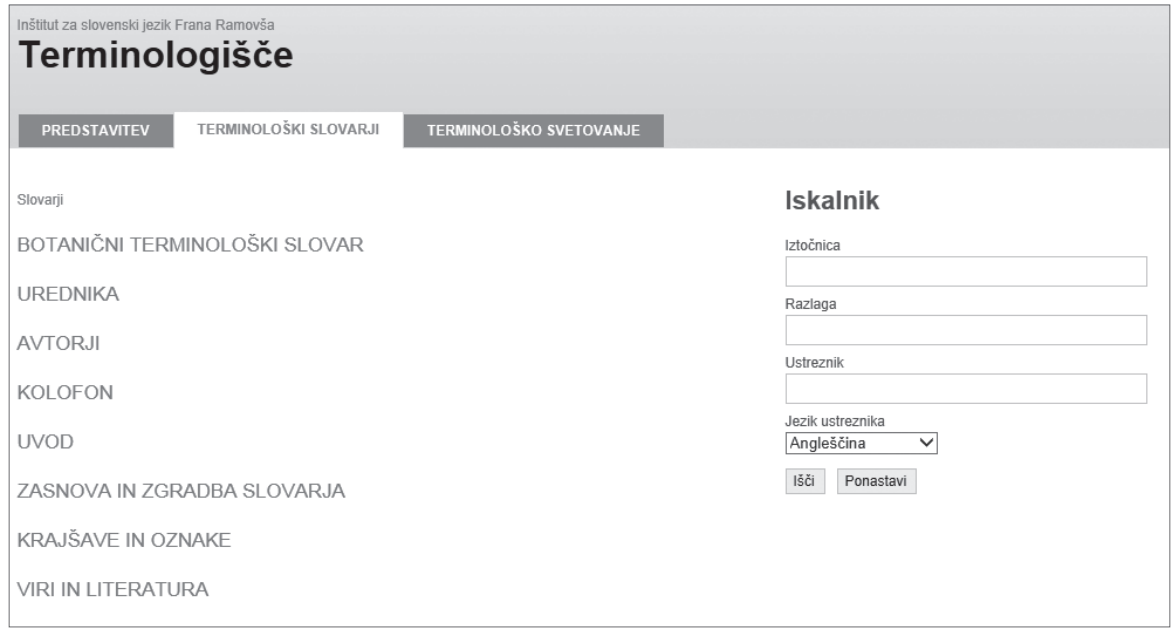

Slika 2: Iskalnik (Botanični terminološki slovar).

Uporabniku prijazen iskalnik omogoča iskanje po iztočnici, po besedi v razlagi (oz. definiciji) in po ustrezniku, pri čemer uporabnik izbere jezik, ki ga zanima (izbira lahko med jeziki, ki so na voljo za posamezni slovar). Da bi uporabniku zagotovili čim bolj popolne informacije, elektronska oblika vključuje vse podatke o slovarju, ki jih ima tudi tiskana izdaja, tj. kolofon, uvod, zgradbo 
in zasnovo slovarja, krajšave in oznake, uporabljene vire in literaturo. Te podatke je mogoče najti ob iskalniku na levi strani. Zahtevnejšemu uporabniku olajšajo iskanje dodatnih informacij o slovarju, ki jih je v slovarskih bazah, ki so organizirane drugače, pogosto težko najti (če so sploh objavljene). Poleg tega je vsak terminološki slovar zgrajen konsistentno, a ne nujno popolnoma enako kot drugi slovarji, saj se področja - delno pa tudi zasnove slovarjev - med seboj razlikujejo. Tu mislimo zlasti na različne krajšave, oznake in podobno, katerih razvezave in pomen $\mathrm{v}$ posameznem slovarju lahko uporabnik hitro najde med podatki levo od iskalnika - slika 2.

Poleg iskanega termina iskalnik najde tudi vse večbesedne termine, ki vsebujejo iskani termin - če npr. uporabnik v Botaničnem terminološkem slovarju $\mathrm{v}$ iskalno polje, po katerem išče iztočnico, vtipka termin list, mu iskalnik poleg slovarskega sestavka z iztočnico list ponudi še 156 drugih večbesednih terminov, ki vsebujejo sestavino list (npr. adultni list, ampleksikavli list, ascidiatni list ...), kar prikazuje slika 3. Tako se ob iskanem terminu pojavijo tudi termini, ki praviloma sodijo v isto pojmovno polje. Če uporabnika zanima tudi kakšen od teh terminov, se s klikom na termin v seznamu pojavi slovarski sestavek $\mathrm{z}$ definicijo in vsemi ostalimi podatki (oz. s kazalko na ustreznejši termin).

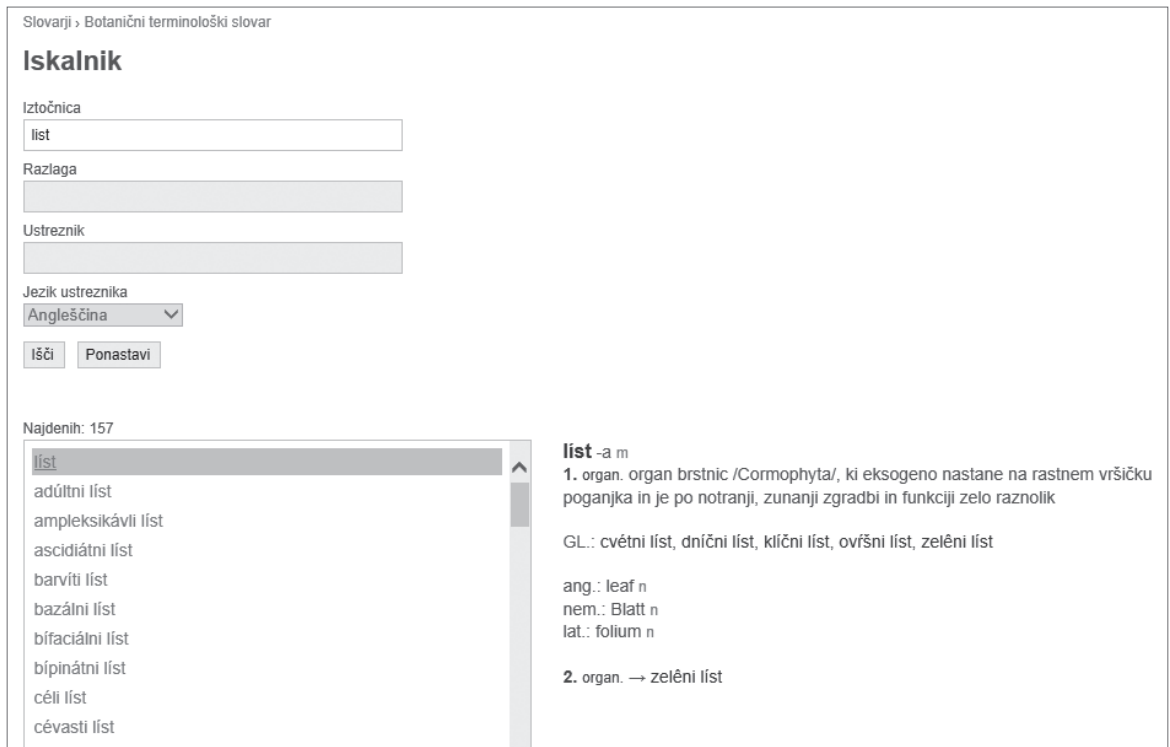

Slika 3: Zadetki za iztočnico list v Botaničnem terminološkem slovarju.

Na sliki 3 vidimo slovarski sestavek za termin list $\mathrm{v}$ Botaničnem terminološkem slovarju. Vsebuje onaglašeno iztočnico, podatek o rodilniški obliki, ki nakazuje sklanjatveni vzorec, in o spolu samostalnika. ${ }^{6}$ Temu sledi strokovni

\footnotetext{
${ }^{6}$ Pri glagolu bi bil dodan podatek o obliki termina v prvi osebi ednine sedanjika, ki nakazuje spregatveni vzorec, in o glagolskem vidu.
} 
označevalnik organ. (organografija), ki termin uvrsti v ustrezno podpodročje znotraj stroke. ${ }^{7}$ Eden od najpomembnejših elementov slovarskega sestavka je razlaga oz. definicija, ki na kratko opredeli pojem glede na njegovo mesto v pojmovnem sistemu stroke. ${ }^{8}$ Sledi podatek o medsebojnih razmerjih med termini, pri terminu list so pri oznaki GL. (glej) navedeni podrejeni pojmi, tj. cvetni list, dnični list, klični list, ovršni list, zeleni list. ${ }^{9} \mathrm{Na}$ koncu so pri vsakem pomenu navedeni še tujejezični ustrezniki. Ker imajo terminološki slovarji praviloma poudarjeno normativno vlogo, so $\mathrm{v}$ njih pogosto tudi kazalke, ki usmerjajo na prednostni termin. Kazalčni slovarski sestavki so zasnovani tako, da s puščico kažejo na ustreznejši oz. prednostni termin. Pri prednostnem terminu najdemo vse ostale informacije o pojmu. Termin lahko ima tudi dva pomena ali celo več pomenov, kar pomeni, da isti termin označuje več različnih pojmov. Istovrstni termini so obravnavani na enak način. Zaradi normativnosti, ki velja v okviru ene stroke, in zaradi medsebojne povezanosti terminov v poimenovalnem sistemu stroke je terminologijo smiselno obravnavati znotraj enega področja (slovarja), kar smo upoštevali tudi pri zasnovi in izvedbi iskalnika za Terminologišče.

Tudi slovarske projekte, ki še nastajajo, nameravamo izdati v tiskani in elektronski obliki, sčasoma bo torej terminoloških slovarjev na Terminologǐ̌ču še več. Tu bomo objavljali tudi nove izdaje že objavljenih slovarjev, trenutno sta v pripravi 2. dopolnjena in popravljena izdaja Farmacevtskega terminološkega slovarja in Botaničnega terminološkega slovarja.

\subsection{Terminološki slovarji na Terminologišču in Franu}

Oktobra 2014 je v okviru Inštituta za slovenski jezik FR ZRC SAZU začel delovati slovarski portal Fran. Fran vsebuje različne slovarje, ki so nastali na Inštitutu za slovenski jezik FR, skupaj več kot 515.000 slovarskih sestavkov. Gre za splošne, zgodovinske, terminološke in narečne slovarje, poleg tega pa je mogoče iskati tudi po dveh svetovalnicah (jezikovni in terminološki) in drugih inštitutskih zbirkah. Ker je iskalnik na Terminologišču namenjen zlasti strokovnjakom, termini pa bi iz različnih razlogov utegnili zanimati tudi splošnega uporabnika (torej nestrokovnjaka), smo se odločili, da Frana in Terminologǐ̌če smiselno povežemo. Fran torej išče tudi po terminoloških slovarjih, pri čemer se izpišejo vse najdene iztočnice. S klikom na iztočnico je uporabnik preusmerjen na Terminologišče, kjer se izpiše celotni slovarski sestavek. Tu lahko uporabnik nadaljuje svoje iskanje v okviru posamezne stroke (oz. slovarja). Če ugotovi, da

\footnotetext{
${ }^{7}$ Strokovni označevalniki niso obvezni v vseh terminoloških slovarjih - glede na specifike področja so $\mathrm{v}$ nekaterih slovarjih bolj smiselni kot $\mathrm{v}$ drugih. V slovarju, ki obravnava botaniko (ta velja za izrazito sistematično vedo), dobro funkcionirajo.

${ }^{8}$ Več o terminoloških definicijah v M. Žagar Karer (2011: 124-138).

${ }^{9}$ Medsebojna razmerja med termini so $\mathrm{v}$ terminoloških slovarjih lahko izražena implicitno (v okviru definicije) ali eksplicitno (kot samostojna kategorija). V botaničnem slovarju so ta razmerja - gre zlasti za razmerja podrednosti in prirednosti - izražena eksplicitno.
} 
ga to ne zanima, se vrne na Frana in išče naprej po Franu. Ker je pri nekaterih pojmovnih skupinah veliko večbesednih terminov, ostane tako tudi iskanje po Franu pregledno. Skratka, Fran omogoča iskanje po različnih vrstah slovarjev, Terminologišče pa je namenjeno bolj usmerjenemu terminološkemu iskanju tako smo poskušali upoštevati potrebe različnih uporabnikov slovarjev.

\section{Terminološko svetovanje}

Že tradicionalno smo se v sekciji ob rednem slovarskem delu ukvarjali tudi s terminološkim svetovanjem (Žagar Karer 2009: 443-448), ob vzpostavitvi Terminologišča pa smo se odločili, da se bomo tej dejavnosti posvetili še bolj, saj so potrebe uporabnikov po hitrem reševanju aktualnih, včasih celo akutnih, terminoloških zadreg velike. Terminološko svetovanje je torej namenjeno strokovnjakom vseh strok, ki se soočajo s konkretnimi poimenovalnimi težavami, pa naj gre za popolnoma nove pojme, ki jih je v slovenščini šele treba poimenovati, ali za že znane pojme, za katere obstaja več poimenovanj, pa strokovnjaki čutijo potrebo po sistemskem poenotenju oz. izbiri najprimernejše rešitve. Strokovnjakom pogosto težave povzroča prevzemanje terminologije iz angleščine, ki je danes aktualna na večini strokovnih področij.

$\mathrm{Z}$ našega vidika terminološko svetovanje torej smiselno dopolnjuje redno slovarsko delo, pri katerem se ukvarjamo z urejanjem celotnega poimenovalnega (in posredno tudi pojmovnega) sistema posameznih strok. Pri tem se lahko najnovejšim terminom posvečamo le v omejenem obsegu, saj se v terminološki slovar praviloma uvrščajo že ustaljeni termini.

Pri pripravljanju odgovorov na terminološka vprašanja sodelujemo vsi redni sodelavci sekcije, zato odgovore vedno zapišemo v obliki skupnega mnenja. Včasih se zgodi, da so mnenja posameznih sodelavcev o konkretnem terminološkem problemu različna - takrat poskušamo na podlagi strokovnih argumentov priti do najustreznejše rešitve. Menimo, da je ta način svetovanja sicer nekoliko zamudnejši, kot če bi odgovor pripravil en sodelavec, a je mnenje za končnega uporabnika bolj relevantno.

Da bi lahko pripravili kakovosten odgovor, je zelo pomembno, da dobimo čim več informacij o konkretnem terminološkem problemu. Bistven je predvsem natančen opis pojma, ki ga iskani termin označuje, zelo koristni pa so tudi podatki o rabi termina $\mathrm{v}$ strokovnih besedilih, morebitne že obstoječe poimenovalne rešitve (v primerih, ko več terminov označuje isti pojem), tujejezični ustrezniki itd. Zato smo pripravili obrazec, preko katerega lahko uporabniki zastavijo svoje vprašanje (slika 4). Obrazec vsebuje tri obvezna polja in tri neobvezna polja. Obvezna polja so: ime in priimek osebe, ki zastavlja vprašanje, njen e-naslov in opis terminološkega problema. Neobvezna polja so: institutcija, na kateri je zaposlena oseba, ki zastavlja vprašanje, morebitne že obstoječe poimenovalne rešitve ter morebitni primeri rabe termina $\mathrm{v}$ besedilih in povezave do njih. 


\section{Novo vprašanje}

Ime in priimek *

E-naslov *

Institucija

Opis terminološkega problema *

Morebitne že obstoječe poimenovalne rešitve

Morebitni primeri rabe termina $v$ besedilih ali povezave do nịh

\section{Pošlji}

Slika 4: Obrazec za terminološko vprašanje.

Pri terminoloških odgovorih upoštevamo osnovna terminološka načela, zlasti ustaljenost, gospodarnost in jezikovnosistemsko ustreznost (več o terminoloških načelih v Gorjanc 1996: 252-254, Vidovič Muha 2000: 116-119 itd.). Pretehtamo, katerim načelom bomo v konkretnem primeru dali prednost. Na podlagi posredovanih podatkov o terminološkem problemu in po pregledu vseh dosegljivih terminoloških virov in splošnih ter specializiranih korpusov se opredelimo do različnih poimenovalnih možnosti in svetujemo, katera re- 
šitev bi bila najustreznejša z vidika terminološke vede. Uporabniki praviloma pričakujejo jasen in nedvoumen odgovor, vendar pa je treba poudariti, da naše mnenje seveda ni obvezujoče. ${ }^{10}$ Terminološko svetovanje je brezplačno, uporabniku odgovorimo osebno po e-pošti v nekaj delovnih dneh (praviloma prej kot $\mathrm{v}$ enem tednu), včasih pa pred končnim odgovorom postavimo še kakšno podvprašanje. Vprašanja in odgovore, za katere mislimo, da so zanimivi za širšo strokovno javnost, objavimo tudi na Terminologišč $u$ (Slika 5), seveda brez imena in priimka osebe, ki je zastavila vprašanje. V letu 2014 smo recimo objavili 33 terminoloških odgovorov iz različnih strokovnjih področij, npr. s področja pedagogike, kazenskega prava, bančništva, lesarstva, agronomije, ekonomije, športa, živinoreje, strojništva, fotografije itd.

\author{
Konfliktni mineral \\ Opis terminološkega problema: \\ Kateri slovenski termin je najprimernejši ustreznik angleškega termina conflict mineral - konfliktni mineral, krvavi \\ mineral ali opisna rešitev mineral s konfliktnih območij -, ki označuje mineral, ki ga uporniška gibanja uporabljajo za \\ financiranje konflikta, katerega cilj je spodkopati legitimno oblast (http://www.sec.gov/rules/final/2012/34-67716.pdf). \\ Vprašanje poslano 5. 3. 2014.
}

\title{
Mnenje terminološke sekcije:
}

V terminološki bazi IATE so dostopne poimenovalne rešitve drugih držav članic EU za konkretni pojem (za slovenščino in hrvaščino je predlagana zveza krvavi mineral): conflict mineral (angleščina), konfliktni minerály (češčina), konfliktmineral (danščina), konfliktialueen mineraali (finščina), minerali dei conflitti (italijanščina), konfliktu izrakteni (latvijščina), minerali ta' kunflitt (malteščina), conflictmineralen (nizozemščina), minério de conflito (portugalščina), konfliktné minerály (slovaščina), konfliktmineraler (švedščina).

Druga možnost je opisno poimenovanje: minerai alimentant le conflit oz. minerais qui alimentent les conflits (francoščina), konflikto zonų naudingosios iškasenos (litovščina), minerały z regionów ogarniętych konfliktami (poljščina), minereuri din zone de conflict (romunščina).

Opisno poimenovanje mineral s konfliktnih območij je v terminologiji manj primerno oz. manj praktično, zato ga odsvetujemo. Na drugi strani pa je skladenjska struktura levega pridevniškega prilastka in samostalniškega jedra najbolj tipična struktura terminov v slovenščini. Mogoče na prvi pogled zvezi konfliktni mineral in krvavi mineral res nista povedni, ampak to v terminologiji, ki je v prvi vrsti namenjena strokovnjakom z določenega področja, ni pomembno. Pri terminologiji gre za konsenz glede termina in ta termin strokovnjak ali posameznik, seznanjen s terminologijo, vedno povezuje z ustreznim pojmom oz. njegovo vsebino.

Omeniti velja tudi razmerje konfliktni/krvavi mineral in konfliktni/krvavi diamant, ki je razmerje nad- in podpomenskosti. Konfliktni diamant je że aktualen v nekaterih besedilih v okviru EU (http://eur-lex.europa.eu/Notice.do? mode=db|\&lang=sl\&ihmlang=sl\&lng1=sl,sl\&lng2=bg, cs, da, de, el, en, es, et, fi, fr, hu, it, It,lv, mt, nl,pl,pt,ro,sk, sl,sv, \&val=261333:cs) V nekaterih dokumentih EU se pojavlja tudi zveza krvava rudnina, ki pa po našem mnenju ni primerna zaradi sestavine rudnina, ki jo imata geološka in gemološka stroka za zastarelo in jo nadomeščata s časovno nevtralnim terminom mineral (gl. Gemološki terminološki slovar, Geološki terminološki slovar).

Konfliktni mineral in krvavi mineral sta metaforični poimenovanji, pri čemer razumevanje metaforike ni kulturno, politično ali družbeno pogojeno in je enako (ne)predvidljivo $v$ angleščini in slovenščini oz. v vseh jezikih in zato tudi v primeru slovenščine ne bi smelo biti sporno. Ker gre v primeru krvavega minerala za stopnjevanje metaforičnosti glede na konfliktni mineral, pa tudi zaradi usklajenosti s konfliktnim diamantom, ki je že aktualen v besedilih v kontekstu EU, za angleški termin conflict mineral predlagamo rabo termina konfliktni mineral.

Slika 5: Primer odgovora (Konfliktni mineral).

${ }^{10}$ Kadar se uporabnik z našimi argumenti ne strinja oz. sporoči še kakšne informacije, ki dodatno pojasnjujejo problem, se strokovna debata praviloma nadaljuje po e-pošti, na Terminologišču pa objavimo končno mnenje. 
Na spletnih straneh Inštituta za slovenski jezik Frana Ramovša ZRC SAZU uspešno deluje tudi Jezikovna svetovalnica (http://isjfr.zrc-sazu.si/sl/svetovalnica), kjer jezikoslovci odgovarjajo na raznovrstna jezikovna vprašanja, ki so pogosto povezana s pravopisnimi temami. Terminološko svetovanje razumemo kot dopolnilo jezikovnemu svetovanju, saj terminološka načela narekujejo nekoliko drugačno obravnavo - terminološki problemi pogosto niso le jezikovne ali jezikovnosistemske narave, ampak je (lahko) problematična že sama opredelitev pojma. Ko skupaj s strokovnjakom razrešimo težave, povezane s pojmom, se pogosto pokaže, da obstaja ustrezna rešitev tudi na poimenovalni, torej izrazni ravni.

\section{Zaključek}

Terminologišče je več kot samo spletno mesto, kjer je mogoče iskati po terminoloških slovarjih. Če uporabnik želene informacije ne dobi v terminoloških slovarjih, lahko za nasvet vpraša sodelavce Sekcije za terminološke slovarje. Tako poskušamo strokovnjakom ponuditi pomoč zlasti pri aktualnih terminoloških vprašanjih in posledično vplivati na ustreznejšo vključitev novih terminov $\mathrm{v}$ poimenovalni sistem stroke.

\section{VIRI IN LITERATURA}

Tanja FAJFAR, 2013: Terminologija in njeno uslovarjanje. Slavistika v regijah - Nova Gorica. Ur. Boža Krakar-Vogel. Ljubljana: Zveza društev Slavistično društvo Slovenije. (Zbornik Slavističnega društva Slovenije, 24). 97-103.

Vojko GORJANC, 1996: Terminologija novejših naravoslovno-tehničnih strok (ob primeru računalništva in jedrske fizike). Jezik in čas. Ur. Ada Vidovič Muha. Ljubljana: Znanstveni inštitut Filozofske fakultete. 251-260.

Borislava KOŠMRLJ-LEVAČIČ, 2007: O terminih z vidika terminografske prakse. Razvoj slovenskega strokovnega jezika. Ur. Irena Orel. Ljubljana: Filozofska fakulteta, Oddelek za slovenistiko, Center za slovenščino kot drugi/tuji jezik. (Obdobja 24). 583-598.

--, 2009: Izdelava ontologij kot faza terminografskega dela ob nastajajočem Botaničnem terminološkem slovarju. Terminologija in sodobna terminografija. Ur. Nina Ledinek, Mojca Žagar Karer, Marjeta Humar. Ljubljana: Založba ZRC, ZRC SAZU. 163-176.

Ada VIDOVIČ MUHA, 2000: Slovensko leksikalno pomenoslovje: Govorica slovarja. Ljubljana: Znanstveni inštitut Filozofske fakultete.

Mojca ŽAGAR KARER, 2005: Determinologizacija (na primeru terminologije fizike). Jezik in slovstvo 50/2, 35-48.

- -, 2009: Terminološko svetovanje med teorijo in prakso. Infrastruktura slovenščine in slovenistike. Ur. Marko Stabej. Ljubljana: Znanstvena založba Filozofske fakultete. (Obdobja 28). 443-448. 
--, 2011: Definicije v slovenskih terminoloških slovarjih. Izzivi sodobnega slovenskega slovaropisja. Ur. Marko Jesenšek. Maribor: Mednarodna založba Oddelka za slovanske jezike in književnosti, Filozofska fakulteta. (Mednarodna knjižna zbirka Zora, 75). 124-138.

\section{TERMINOLOGIŠČE - A PLACE TO SEARCH FOR TERMINOLOGY}

In this article we present Terminologišče, the website of the Terminological Section of the Fran Ramovš Institute of the Slovenian Language, and its structure. Terminologišče is divided into three parts. Part one consists of an overview of the Section and its dictionary projects, a short description of the methodology used for compiling terminological dictionaries, a selection of articles on terminological theory, and some monographs of the Section's members. Part two is dedicated to free electronic editions of terminological dictionaries published in printed form after the year 2000, namely, 10 explanatory terminological dictionaries (Dictionary of automatic control, systems and robotics; Botanical terminological dictionary; Pharmaceutical terminological dictionary; Slovene dictionary of skiing terminology; Dictionary of theatre terminology; Dictionary of beekeeping terminology; Geological terminological dictionary; Gemological terminological dictionary; Geographical terminological dictionary; and Dictionary of hiking terminology). All new dictionaries, the ones that have yet to be published, will also be published on the website.

The search engine is user-friendly. It enables users to search by headwords, individual words that are part of the explanation, or foreign counterparts. The electronic edition contains all the information about a dictionary that is also given in printed edition, such as the colophon, the introduction, a chapter on the structure and outline of a dictionary, an explanation of abbreviations and labels, and sources and literature. In this way a user has all the information about a specific dictionary. The third part is intended for experts with questions on terminology. In order to receive terminological advice they have to fill out an electronic form. The members of the Section answer the questions by e-mail. If a question might be interesting for other terminology experts, it is also published on the site of Terminologišče. 